\title{
Comparison of maternal characteristics in low birth weight and normal birth weight infants
}

\author{
M. Nazari, ${ }^{1,2}$ S.Y. Sharifah Zainiyah, ${ }^{2}$ M.S. Lye, ${ }^{2}$ M.S. Zalilah ${ }^{3}$ and M. Heidarzadeh ${ }^{4}$
}



ABSTRACT Low birth weight is a key determinant in the risk of morbidity and mortality in the neonatal period and during childhood. This unmatched case-control study in Hamadan, Islamic Republic of Iran, compared the characteristics of mothers of low- and normal-birth-weight infants. Maternal sociodemographic data, pregnancy history, anthropometric data and cord plasma zinc level were collected from 134 mothers of low-birth-weight infants and 134 mothers of normal infants at the time of delivery. Significant differences in maternal characteristics namely gravida, parity, body mass index, maternal weight gain during pregnancy and plasma cord blood zinc were found between low- and normal-birth-weight infants. There were no significant differences in maternal age, maternal education, maternal occupation, family income, previous abortion, previous preterm labour, birth interval, type of clinic and place of residence between the 2 groups.

Comparaison des caractéristiques des mères de nourrissons ayant un poids de naissance faible et un poids de naissance normal

RÉSUMÉ Un faible poids de naissance constitue un facteur déterminant du risque de morbi-mortalité pendant la période néonatale et l'enfance. La présente étude cas-témoins non appariés menée à Hamadan (République islamique d'Iran) a comparé les caractéristiques des mères de nourrissons ayant un poids de naissance faible ou normal. Les données sociodémographiques, anthropométriques et les antécédents gravidiques ont été recueillis et le taux de zinc plasmatique dans le cordon a été analysé à l'accouchement chez 134 mères ayant donné naissance à un nourrisson de faible poids et chez 134 mères ayant donné naissance à un nourrisson de poids normal. Des différences significatives dans les caractéristiques maternelles, à savoir la gestité et la parité, l'indice de masse corporelle, la prise de poids de la mère pendant la grossesse et le taux de zinc plasmatique dans le sang de cordon, ont été observées entre les deux groupes. En revanche, aucune différence importante n'a été retrouvée pour l'âge, le niveau d'études, la profession, le revenu familial, les antécédents d'avortement et de travail prématuré, l'espacement des naissances, le type d'établissement de soins choisi et le lieu de résidence des mères des deux groupes.

${ }^{\top}$ Research Centre for Child and Maternity Care; Hamadan University of Medical Sciences, Hamadan, Islamic Republic of Iran (Correspondence to M. Nazari:Mozhgannazari2003@yahoo.com;Moj.na1346@gmail.com).

${ }^{2}$ Department of Community Health; ${ }^{3}$ Department of Nutrition and Dietetics, Faculty of Medicine and Health Sciences, University Putra Malaysia, Selangor, Malaysia.

${ }^{4}$ Department of Neonatology, Faculty of Medicine and Health Sciences, Tabriz University of Medical Sciences, Islamic Republic of Iran.

Received: 26/04/12; accepted: 19/06/12 


\section{Introduction}

Low birth weight (LBW), defined as weight $<2500 \mathrm{~g}$ at the time of birth [1], predicts normal growth during infancy and childhood [2] and is a key determinant in the risk of morbidity and mortality in this period. The World Health Organization (WHO) reported that $11.0 \%$ of infants in the Eastern Mediterranean Region (EMR) have LBW and that LBW and prematurity was the cause of $43.0 \%$ of mortality in children $<5$ years of age in the Region [3]. As the incidence of LBW is one of the best indicators for evaluating the success of maternal and child programmes $[4,5] \mathrm{LBW}$ has featured in the health targets of a number of international organizations. Reducing the incidence of LBW babies by at least one-third by 2010 was one of the goals of $\mathrm{WHO}[6]$ and a United Nations resolution in 2000 [7]. Since $38.0 \%$ of child mortality occurs during the first month of birth and is directly related to birth weight, LBW is also an important indicator for monitoring the achievement of Millennium Developmental Goal 4, to reduce child mortality by two-thirds by $2015[6,8,9]$.

In the Islamic Republic of Iran $8.6 \%$ of infants are borne with LBW and this represents the most important cause of infant mortality in the past 2 decades [10]. It has been established that LBW infants are at greater risk for certain diseases such as cardiovascular and metabolic diseases in adulthood [11]. LBW may also lead to a vicious cycle beginning with a stunted child, followed by a thin adolescent and leading to thin mothers during pregnancy [12]; these mothers are at increased risk of maternal morbidity and mortality [13]. It is therefore important to study the characteristics of pregnant women so that interventions can be undertaken aimed at promoting mothers' health during the antenatal period and hence to achieve the goal of healthy normal birth weight (NBW) babies. This unmatched case-control study in Hamadan, Islamic Republic of Iran, part of a larger study, compared the maternal characteristics of 2 groups of infants (LBW and NBW) at the time of birth.

\section{Methods}

\section{Study setting and sample}

This study was carried out in the labour ward of Fatemieh hospital, a referral and teaching hospital for the Hamadan University of Medical Science in Hamadan, Islamic Republic of Iran. The hospital receives pregnant women who are referred from peripheral antenatal care and other smaller hospitals in the province after screening for risks of obstetric complications. It has 1 labour ward with a capacity of 20 beds and 1 neonatal intensive care unit ward. There are nearly 20 deliveries per day.

In this study infants with birth weight $<2500 \mathrm{~g}$ and their mothers were selected as cases and infants with birth weight between 2500-4000 g were selected as controls. Infants with any obvious congenital anomalies were excluded from this study. Mothers with any known risk factor for delivering LBW infants were excluded from this study. We therefore excluded: mothers who were suffering from hypertension, renal disease, respiratory disease, diabetes, lupus, anaemia or other significant medical complications such as heart disease, gastrointestinal disease, infectious diseases; mothers with multiple pregnancy, prolonged labour, fever during labour or malformations of the reproductive system which cause fetal growth retardation (e.g. unicorn uterus, bicorn uterus); mothers who were smokers or consumed alcohol or illicit drugs; and mothers who had or previous record of trauma or any abuse or severe stress such as death of family member.
A sample size of 134 per group was required to detect an odds ratio (OR) of 2 for an unmatched study, with a power of 0.8 and alpha level of 0.05 .

\section{Data collection}

The study was conducted from 6 December 2009 to 18 October 2010. Recruitment was conducted by 6 trained midwives who assisted in obtaining informed consent, recruiting, filling the proforma and taking blood samples.

The gestational age of infants was determined by the first day of the last menstrual period, ultrasound in the first and third trimester of pregnancy and also using the new Ballard score. All premature infants and those with intrauterine growth restriction with birth weight $<2500 \mathrm{~g}$ were included in this study. The infant's weight was determined to the nearest $1 \mathrm{~g}$ by an electronic infant scale, calibrated weekly. Then $3 \mathrm{~mL}$ of cord blood was taken through the umbilical cord vein immediately after delivery and before placenta delivery to avoid clotting by using $5 \mathrm{~mL}$ disposable plastic zinc-free syringe with a stainless needle of the same batch. The blood was put into a zinc-free uncontaminated EDTAK3 polyethylene tube labelled with the serial number of the mother. The blood samples were centrifuged at $4500 \mathrm{rpm}$ for 15 minutes. The maximum time from taking specimen to freezing was $<1$ hour. The plasma was kept frozen in plastic microtubes at $-20^{\circ} \mathrm{C}$ until atomic absorption spectrophotometry was used to determine the concentration of zinc.

Zinc status was divided into 3 categories: severe zinc deficiency < $60 \mu \mathrm{g} / \mathrm{dL}$, mild to moderate zinc deficiency between $60-70 \mu \mathrm{g} / \mathrm{dL}$ and normal zinc level between 71-150 $\mu \mathrm{g} / \mathrm{dL}[14]$.

\section{Ethical considerations}

Ethical approval for the study was obtained from the ethics committee 
of the Faculty of Medicine and Health Sciences, University Putra Malaysia as well as the ethics committee of the Medical Science University of Hamadan, Islamic Republic of Iran. Informed consent was obtained from the mothers before participating in this study. To avoid pricking the subjects, cord blood was used.

\section{Analysis}

The data were revised, coded and analysed using SPSS, version 16 . Descriptive statistics were computed for all variables. Non-parametric tests were used since the distributions of some variables were not normal. Chisquared or Fisher exact tests were used to test the differences between maternal characteristics among LBW and NBW for categorical variables, while Student $t$-test was used for continuous variables. $P<0.05$ was considered statistically significant.

\section{Results}

\section{Mothers' demographic characteristics}

Data were collected from 268 newborns (134 cases, 134 controls). Table 1 shows a comparison between LBW and NBW infants in terms of maternal sociodemographic characteristics. The median age was 24 years (range 15-50 years) and 24 years (range 15-41 years) in cases and controls respectively. There were no significant differences in mother's age, education or occupation or family income between cases and controls.

\section{Mothers' obstetric history}

Table 2 shows the comparison between the obstetric history of mothers in the case and control groups. There were significant differences in gravida $(P<0.001)$ and parity $(P<0.001)$ between cases and controls, whereas there were no significant differences between previous abortion, previous LBW, birth interval and previous preterm labour among cases and controls. Primigravida and primiparous mothers were more at risk of having a LBW infant than multigravida and multiparous mothers.

\section{Mothers' anthropometric characteristics}

Fewer mothers in the LBW group than the mothers of NBW infants were classified as underweight $(7.0 \%$ versus $14.6 \%$ ), $78.6 \%$ of LBW infants had normal weight mothers compared with $58.5 \%$ of NBW mothers and fewer LBW than NBW infants had overweight or obese mothers ( $14.7 \%$ versus $26.9 \%$ ). The range of maternal BMI in the LBW infants group was between 17.0 and $35.2 \mathrm{~kg} / \mathrm{m}^{2}$ and in the NBW group was between $15.6-37.7 \mathrm{~kg} / \mathrm{m}^{2}$. Mean maternal pre-pregnancy BMI

\begin{tabular}{|c|c|c|c|c|c|c|}
\hline \multirow[t]{3}{*}{ Maternal characteristic } & \multicolumn{4}{|c|}{ Infant birth weight group } & \multirow[t]{3}{*}{$x^{2}$-test } & \multirow[t]{3}{*}{$P$-value } \\
\hline & \multicolumn{2}{|c|}{ LBW $(n=134)$} & \multicolumn{2}{|c|}{ NBW $(n=134)$} & & \\
\hline & No. & $\%$ & No. & $\%$ & & \\
\hline Age (years) ${ }^{a}$ & & & & & 0.262 & 0.877 \\
\hline$<20$ & 21 & 15.8 & 21 & 15.9 & & \\
\hline $21-35$ & 104 & 78.2 & 101 & 76.5 & & \\
\hline$>35$ & 8 & 6.0 & 10 & 7.6 & & \\
\hline Education $^{b}$ & & & & & 7.01 & 0.220 \\
\hline Non-formal education & 11 & 8.3 & 9 & 6.7 & & \\
\hline Primary school or literate & 50 & 37.6 & 49 & 36.6 & & \\
\hline Middle school certification & 20 & 15.0 & 36 & 26.9 & & \\
\hline High school certification & 12 & 9.0 & 11 & 8.2 & & \\
\hline Intermediate or post high school diploma & 32 & 24.1 & 25 & 18.7 & & \\
\hline Graduate or postgraduate & 8 & 6.0 & 4 & 3.0 & & \\
\hline Occupation & & & & & 2.06 & 0.357 \\
\hline Housewife & 127 & 94.8 & 131 & 98.0 & & \\
\hline Clerical & 7 & 5.2 & 3 & 2.2 & & \\
\hline Family income $\left(\times 10^{3} \mathrm{rials} / \text { month }\right)^{c}$ & & & & & 6.95 & 0.326 \\
\hline$\leq 1000$ & 9 & 6.7 & 6 & 4.5 & & \\
\hline $1000-<3000$ & 42 & 31.3 & 37 & 28.0 & & \\
\hline $3000-<5000$ & 56 & 41.8 & 71 & 53.8 & & \\
\hline $5000-<7000$ & 18 & 13.4 & 15 & 11.4 & & \\
\hline$\geq 7000$ & 8 & 3.8 & 3 & 2.3 & & \\
\hline
\end{tabular}

${ }^{a}$ Missing $=3$ cases $;{ }^{b}$ Missing $=1$ case $;{ }^{c} 10000$ rials $=$ approx. US\$ 1 . 


\begin{tabular}{|c|c|c|c|c|c|}
\hline \multirow{3}{*}{ Maternal obstetric history } & \multicolumn{4}{|c|}{ Infant birth weight group } & \multirow[t]{3}{*}{$P$-value } \\
\hline & \multicolumn{2}{|c|}{$\begin{array}{c}\text { LBW } \\
(n=134)\end{array}$} & \multicolumn{2}{|c|}{$\begin{array}{c}\text { NBW } \\
(n=134)\end{array}$} & \\
\hline & No. & $\%$ & No. & $\%$ & \\
\hline Gravida & & & & & $<0.001^{\mathrm{b}}$ \\
\hline Primigravida & 92 & 68.7 & 59 & 44.0 & \\
\hline Multigravida & 42 & 31.3 & 75 & 56.0 & \\
\hline Parity & & & & & $<0.001^{\mathrm{b}}$ \\
\hline Primipara & 100 & 74.6 & 64 & 47.8 & \\
\hline Multipara & 34 & 25.4 & 70 & 52.2 & \\
\hline History of abortion & & & & & $0.260^{c}$ \\
\hline No & 121 & 90.3 & 115 & 85.8 & \\
\hline Yes, 1 & 12 & 9.0 & 17 & 12.7 & \\
\hline Yes, $\geq 2$ & 1 & 0.7 & 2 & 1.5 & \\
\hline Birth interval (years) ${ }^{a}$ & & & & & $0.714^{\mathrm{b}}$ \\
\hline$<3$ & 3 & 6.2 & 7 & 10.4 & \\
\hline$\geq 3$ & 30 & 93.8 & 60 & 89.6 & \\
\hline Previous $L B W$ & & & & & $0.103^{b}$ \\
\hline No & 126 & 94.0 & 132 & 98.5 & \\
\hline Yes & 8 & 6.0 & 2 & 1.5 & \\
\hline Previous preterm labour & & & & & $0.622^{\mathrm{b}}$ \\
\hline No & 131 & 97.8 & 133 & 99.3 & \\
\hline Yes & 3 & 2.2 & 1 & 0.7 & \\
\hline
\end{tabular}

aThere were 4 missing values, and because birth interval was only relevant for multiparous women and there were 100 multiparas, values for primiparous mothers were not computed; ${ }^{b}$ Fisher exact test; ${ }^{c} \chi^{2}=4.015$.

was significantly lower in LBW [21.9 $\left.(\mathrm{SD} 3.14) \mathrm{kg} / \mathrm{m}^{2}\right]$ than NBW infants $\left[22.8(\mathrm{SD} 4.01) \mathrm{kg} / \mathrm{m}^{2}\right](t=2.74, \mathrm{df}=$ $244, P=0.033)($ Table 3$)$.

Mean maternal weight gain during pregnancy was lower in mothers of LBW than NBW infants. Mean weight gain during pregnancy was also significantly lower in mothers of LBW $[10.2$ $(\mathrm{SD} 4.36) \mathrm{kg}]$ than NBW $[12.2(\mathrm{SD}$ $5.68) \mathrm{kg}]$ infants $(t=3.26, \mathrm{df}=265, P$ $<0.001$ ) (Table 3). In both LBW and
NBW groups some mothers had hyperemesis gravidarum in first trimester of pregnancy, so their weight loss was more than weight gain during pregnancy. In this study we had 4 mothers with weight loss during pregnancy (3 mothers in NBW group and 1 mother in LBW group), but the effect of weight loss was not taken into consideration.

\section{Cord plasma zinc concentration}

Table 4 showed the cord blood plasma zinc concentration was significantly different between LBW and NBW infants. Significantly more LBW infants had severe zinc deficiency than NBW infants $\left(\chi^{2}=6.93, P=0.031\right)$.

\section{Mothers' antenatal care}

Almost all mothers in both case and control groups had attended government clinics. There was no association between the type of clinic and infant birth weight $\left(\chi^{2}=3.06, P=0.271\right)$. The percentage of NBW infants was higher in urban mothers. However Fisher exact

\begin{tabular}{|c|c|c|c|c|c|c|c|}
\hline \multirow[t]{3}{*}{ Variable } & \multicolumn{4}{|c|}{ Infant birth weight group } & \multirow[t]{3}{*}{$t$-test } & \multirow[t]{3}{*}{ df } & \multirow[t]{3}{*}{$P$-value } \\
\hline & \multicolumn{2}{|c|}{$\begin{array}{c}\text { LBW } \\
(n=134)\end{array}$} & \multicolumn{2}{|c|}{$\begin{array}{c}\text { NBW } \\
(n=134)\end{array}$} & & & \\
\hline & Mean (SD) & Range & Mean (SD) & Range & & & \\
\hline Pre-pregnancy BMI (kg/m²) & $21.9(3.14)$ & 17.0 to 35.2 & $22.8(4.01)$ & 15.6 to 37.7 & 2.14 & 244 & 0.003 \\
\hline Weight gain during pregnancy $(\mathrm{kg})$ & $10.2(4.36)$ & -3 to +22 & $12.2(5.68)$ & -5 to +34 & 3.25 & 265 & $<0.001$ \\
\hline
\end{tabular}

$S D=$ standard deviation; $d f=$ degrees offreedom . 


\begin{tabular}{|c|c|c|c|c|c|c|}
\hline \multirow[t]{3}{*}{ Cord blood plasma zinc level } & \multicolumn{4}{|c|}{ Infant birth weight group } & \multirow[t]{3}{*}{$x^{2}$-test } & \multirow[t]{3}{*}{$P$-value } \\
\hline & \multicolumn{2}{|c|}{$\begin{array}{c}\text { LBW } \\
(n=134)\end{array}$} & \multicolumn{2}{|c|}{$\begin{array}{l}\text { Normal } \\
(n=134)\end{array}$} & & \\
\hline & No. & $\%$ & No. & $\%$ & & \\
\hline Normal & 116 & 86.6 & 121 & 90.3 & 6.93 & 0.031 \\
\hline Mild to moderate zinc deficiency & 9 & 6.7 & 12 & 9.0 & & \\
\hline Severe zinc deficiency & 9 & 6.7 & 1 & 0.7 & & \\
\hline
\end{tabular}

test did not show any significant association between place of maternal residence and infant birth weight $(P=$ 0.434) (Table 5).

\section{Discussion}

Our study showed that there was no significant difference in maternal age among LBW and NBW infants, a finding which is consistent with some previous research $[15,16]$, although other studies suggested that maternal age was a risk factor for LBW infants $[4,10]$. A study in Poland showed that mother's age $<20$ years was a protective factor against LBW infants [16]. Conversely, in Taiwan LBW was more common in mothers $<20$ years old and $>30$ years old [17]. Mothers' age $>40$ years can be a strong risk factor for extremely LBW [15]. This contradictory effect may be related to the socioeconomic status of teenage mothers and other risk factors such as smoking, alcohol use, illicit drug use and pregnancy outside of marriage in teenage groups. Generally the risk of LBW in mothers aged between 20-35 years is lower than in teenage mothers as well as older mothers due to many reasons. A possible explanation for higher risk of LBW among younger mothers is that they are still developing and their need for minerals and vitamins is greater than among older mothers. Another reason may be the limited knowledge of these younger mothers about healthy lifestyles and preparation during the antenatal period. The risk of LBW among older mothers may be related to many risk factors such as cardiovascular disease, hypertension, diabetes and other diseases that frequently affect older mothers. The reason for the non-significant difference in maternal age between LBW and NBW groups in this study may be the new protocol for high-risk mothers during prenatal care in the Islamic Republic of Iran. Mothers aged <
18 years and $>35$ years are considered an at-risk group and receive special prenatal care during pregnancy, which may compensate for the effect of age on infant birth weight.

The present study showed that there were no significant differences between maternal education among LBW and NBW infants, which is consistent with some other studies suggesting that mothers' levels of education did not affect infants' birth weight $[4,15]$. Other studies showed that a low level of maternal education was a predictor of LBW $[10,14,18]$. Maternal "dietary literacy" has been shown to influence the zinc status of mothers $[14,18]$.

Our data also indicated that maternal occupation was not different between the case and control groups and this supports the findings of other researchers $[3,10,15]$. A possible reason for this finding is the homogenous nature of occupation, as the great majority of the mothers in our study were

\begin{tabular}{|c|c|c|c|c|c|c|}
\hline \multirow[t]{3}{*}{ Variable } & \multicolumn{4}{|c|}{ Infant birth weight group } & \multirow[t]{3}{*}{$x^{2}$-test } & \multirow[t]{3}{*}{$P$-value } \\
\hline & \multicolumn{2}{|c|}{$\begin{array}{c}\text { LBW } \\
(n=134)\end{array}$} & \multicolumn{2}{|c|}{$\begin{array}{c}\text { NBW } \\
(n=134)\end{array}$} & & \\
\hline & No. & $\%$ & No. & $\%$ & & \\
\hline Clinic & & & & & 3.06 & 0.217 \\
\hline Government & 127 & 94.8 & 124 & 92.5 & & \\
\hline Private & 7 & 5.2 & 7 & 5.3 & & \\
\hline Both & 0 & 0.0 & 3 & 2.2 & & \\
\hline Place of residence & & & & & & $0.434^{\mathrm{a}}$ \\
\hline Urban & 40 & 29.9 & 47 & 35.1 & & \\
\hline Rural & 94 & 70.1 & 87 & 64.9 & & \\
\hline
\end{tabular}

${ }^{a}$ Fisher exact test. 
housewives. Hence it was not possible to study the effect of job on birth weight in this study.

Mean family incomes for LBW and NBW infants were similar. Other studies showed that higher socioeconomic status reduced the risk of LBW especially very LBW and prematurity [18]. The findings of Aydemir et al. showed that there were significant differences between plasma zinc levels among mothers of different socioeconomic status. Moreover, they did not find any relationship between plasma zinc levels and infant anthropometric parameters [19]. Maternal nutritional needs increase during pregnancy. Unfortunately, lack of knowledge about diet and lower family income are important risk factors for inadequate intake of nutrients in the majority of pregnant mothers.

Our study showed significant differences between the case and control groups for mothers' gravida and parity. Primiparous mothers were more at risk having LBW infants in comparison with multiparous mothers. The risk of very LBW in these mothers is greater than multiparous mothers $[1,17]$. The possible explanation for higher birth weight in multiparous mothers compared with primiparous mothers, except in older mothers, is the higher uterine blood circulation in multiparous mothers [20].

Other obstetric history variables - birth interval, previous LBW and previous preterm labour-were not significantly different between case and control groups. This nonsignificant difference may be related to the small sample size in the group of mothers with $<3$ years birth interval. Conversely, the results of Roudbari et al. and Bernabe et al. were contradictory $[10,21]$. They reported that birth intervals of $<3$ years had a significant effect on pregnancy outcome and increased risk of LBW. O'Connor et al. also stated that adequate birth interval and using family planning were one of the best ways to reduce the risk of LBW infants [22]. According to the new protocol for prenatal care in Islamic Republic of Iran mothers with a history of previous LBW or preterm labour receive increased prenatal care under the supervision of an obstetrician/gynaecologist during pregnancy, so this extra level of care may have decreased the risk of LBW and premature birth.

Our study also showed that maternal pre-pregnancy BMI was significantly different between the case and control groups. Likewise, obese women were at more risk for delivering LBW infants, because obesity increases the risk of hypertensive disease and diabetes [20]. However, findings by other researchers suggested that the maternal pre-pregnancy BMI is associated with infant birth weight $[17,23]$. Both underweight and overweight in mothers can affect pregnancy outcomes [24]. Higher BMI and multiparity were associated with increased risk of having large gestational age infants. Also the risk of LBW was higher in thin and normal weight mothers compared with overweight and obese mothers [23]. The findings by Goldenberg et al. showed that a lower pre-pregnancy BMI may cause preterm in these mothers [25]. Conversely the association between maternal pre-pregnancy BMI and LBW infants was not significant in a study in Rasht, Islamic Republic of Iran [3]. The possible explanation for higher risk of LBW among overweight and obese mothers in our study may be related to advice on weight gain limitation given by health-care workers to overweight and obese mothers during pregnancy. Tamura et al. also found that there was a negative and significant relationship between prepregnancy BMI and maternal zinc concentration [26].

According to WHO the recommended weight gain during pregnancy is $\geq 15 \mathrm{~kg}$ for underweight mothers,
$10-14.99 \mathrm{~kg}$ for normal weight mothers and $<10 \mathrm{~kg}$ for overweight and obese mothers [27]. In this study the maternal weight gain during pregnan$\mathrm{cy}$ in the case and control groups was significantly different. This result was similar to the findings of several studies which demonstrated that maternal weight gain during pregnancy was an important risk factor for LBW infants $[10,17]$. The risk of LBW was significantly lower in mothers who had sufficient weight gain during pregnancy compared with mothers who did not have adequate weight gain [28-30].

The type of clinic and place of residence were not significantly different between case and control groups.

\section{Conclusion}

Maternal pre-pregnancy BMI, maternal weight gain during pregnancy, gravida, parity and cord blood plasma zinc were significantly different between LBW and NBW infants, but there was no significant difference in maternal age, maternal education, maternal occupation, family income, previous abortion, previous preterm labour, birth interval, type of clinic or place of maternal residence between LBW and NBW infants.

\section{Acknowledgements}

We would like to extend our gratitude to the mothers who participated in this study, as well as the medical staff in Fatemieh hospital for their invaluable assistance in this research.

Funding: We would like to express our deepest gratitude to the Iranian Ministry of Health and Medical Education, as well as the Mother and Child Care Research Centre of Hamadan University of Medical and Health Sciences for supporting this research.

Competing interests: None declared. 


\section{References}

1. Cunningham L, Bloom H, Rouse S. Williams' obstetrics, 23 ed. New York, McGraw-Hill, 2010.

2. Roberfroid D et al.; MISAME Study Group. Effects of maternal multiple micronutrient supplementation on fetal growth: a double-blind randomized controlled trial in rural Burkina Faso. American Journal of Clinical Nutrition, 2008, 88:13301340.

3. Maddah $\mathrm{M}$ et al. Social factors and pregnancy weight gain in relation to infant birth weight: a study in public health centers in Rasht, Iran. European Journal of Clinical Nutrition, 2005, 59:1208-1212.

4. Vahdaninia M, Tavafian S, Montazeri A. Correlates of low birth weight in term pregnancies: a retrospective study from Iran. BMC Pregnancy and Childbirth, 2008, 8:1-5.

5. Zulfiqar $\mathrm{AB}$ et al. Outcomes in developing countries: a review of the evidence community-based interventions for improving perinatal and neonatal health. Pediatrics, 2005, 115:519-617.

6. Wardlaw $T$ et al. Low birth weight country regional and global estimates. New York; United Nations Children's Fund/World Health Organization, 2004.

7. Haggaz AD, Radi EA, Adam I. Anaemia and low birthweight in western Sudan. Transactions of the Royal Society of Tropical Medicine and Hygiene, 2010, 104:234-236.

8. Khor GL. Importance of nutrition in achieving the Millennium Development Goals. Malaysian Journal of Medicine and Health Sciences, 2008, 4(1):1-21.

9. World health statistics 2011. Geneva, World Health Organization, 2011.

10. Roudbari M, Yaghmaei M, Soheili M. Prevalence and risk factors of low-birth-weight infants in Zahedan, Islamic Republic of Iran. Eastern Mediterranean Health Journal, 2007, 13:838-845.

11. Romano $\mathrm{T}$ et al. Prenatal growth restriction and postnatal growth restriction followed by accelerated growth independently program reduced bone growth and strength. Bone, 2009, 45:132-141.

12. Elizabeth KE, Krishnan V, Zachariah P. Auxologic, biochemical and clinical $(\mathrm{ABC})$ profile of low birth weight babies- a 2-year prospective study. Journal of Tropical Pediatrics, 2007, 53:374-382.

13. Friis $\mathrm{H}$ et al. Effect of multimicronutrient supplementation on gestational length and birth size: a randomized, placebocontrolled, double-blind effectiveness trial in Zimbabwe. American Journal of Clinical Nutrition, 2004, 80:178-184.

14. Borna $\mathrm{S}$ et al. A comparative study of Zinc deficiency prevalence in pregnant and non pregnant women. Tehran University Medical Journal, 2009, 67:360-367.

15. Farajzadegan $Z$ et al. Could zinc supplementation in pregnancy improve infancy outcomes? Shiraz E-Medical Journal, 2007; 8 (2):80-86.

16. Borkowski WO, Mielniczuk H. [The influence of social and health factors including pregnancy weight gain rate and pre-pregnancy body mass on low birth weight of the infant]. Wpływ wybranych czynników społecznych i zdrowotnych, w tym tempa przyrostu masy ciała w ciazy i masy przed ciaza, na mała mase urodzeniowa noworodka. Ginekologia Polska, 2008, 79:415-421.

17. Li Y-M, Chang T-K. Maternal demographic and psyhosocial factors associated with low birth weight in eastern Taiwan. Kaohsiung Journal of Medical Sciences, 2005, 21:502-510.

18. Schulpis $\mathrm{KH}$ et al. The effect of nutritional habits on maternalneonatal zinc and magnesium levels in Greeks and Albanians. European E-Journal of Clinical Nutrition and Metabolism, 2009, 4(4):e176-e180.

19. Aydemir $\mathrm{F}$ et al. Plasma zinc levels during pregnancy and its relationship to maternal and neonatal characteristics: a longitudinal study. Biological Trace Element Research, 2003, 91:193-202.

20. Rosenberg TJ et al. Maternal obesity and diabetes as risk factors for adverse pregnancy outcomes: differences among 4 racial/ethnic groups. American Journal of Public Health, 2005, 95:1545-1551.

21. Valero De Bernabé J et al. Risk factors for low birth weight: a review. European Journal of Obstetrics, Gynecology, and Reproductive Biology, 2004, 116:3-15.

22. O'Connor J, Nolan K, O'Neill C. State-level health policy to improve birth outcomes and reduce infant mortality. Health Promotion Practice, 2005, 6:12-22.

23. Williamson CS. Nutrition in pregnancy. Nutrition Bulletin, 2006, 31:28-59.

24. Cruz ML et al. Association of body mass index of HIV-1-infected pregnant women and infant birth weight, body mass index, length, and head circumference: the National Institute of Child Health and Human Development International Site Development Initiative Perinatal Study. Nutrition Research, 2007, 27:685-691.

25. Goldenberg RL et al. Epidemiology and causes of preterm birth. Lancet, 2008, 371:75-84

26. Tamura $\mathrm{T}$ et al. Relationship between pre-pregnancy BMI and plasma zinc concentrations in early pregnancy. British Journal of Nutrition, 2004, 91:773-777.

27. Ota E et al. Maternal body mass index and gestational weight gain and their association with perinatal outcomes in Viet Nam. Bulletin of the World Health Organization, 2011, 89:127136.

28. Ricketts SA, Murray EK, Schwalberg R. Reducing low birthweight by resolving risks: results from Colorado's prenatal plus program. American Journal of Public Health, 2005, 95:1952-1957.

29. Siega-Riz AM et al. A systematic review of outcomes of maternal weight gain according to the Institute of Medicine recommendations: birth weight, fetal growth, and postpartum weight retention. American Journal of Obstetrics and Gynecology, 2009, 201:331-339.

30. Hulsey TC et al. Maternal prepregnant body mass index and weight gain related to low birth weight in South Carolina. Southern Medical Journal, 2005, 98:411-415. 